\title{
Control of food intake by MC4-R signaling in the lateral hypothalamus, nucleus accumbens shell and ventral tegmental area: Interactions with ethanol
}

\author{
Jose M. Lerma-Cabrera ${ }^{a}$, Francisca Carvajal ${ }^{a}$, Lourdes de la Torre ${ }^{a}$, Leticia de la Fuente ${ }^{c}$, \\ Montserrat Navarro $^{b}$, Todd E. Thiele ${ }^{\mathrm{b}}$, and Inmaculada Cubero ${ }^{\mathrm{a},{ }^{*}}$ \\ aDepartamento de Neurociencia y Ciencias de la Salud, Universidad de Almería, Almería, 04120, \\ Spain \\ bDepartment of Psychology, University of North Carolina at Chapel Hill, CB\#3270, Chapel Hill, \\ NC, 27599-3270, USA \\ 'Departamento de Ciencias humanas y sociales, Universidad de Almería, Almería, 04120, Spain
}

\section{Abstract}

The Melanocortin system is involved in animal models of obesity and anorexia-cachexia and MC4 receptors (MC4-R) are currently a target system for the development of drugs aimed to treat obesity and eating disorders in humans. Previous evidence suggest that feeding peptides might lack their orexigenic activity while stimulate ethanol intake. The present study comparatively evaluated food intake (4-h interval) in Sprague-Dawley (SD) rats drinking ethanol (6\% w/v, 2 bottle choice paradigm) (EE group) and ethanol-naïve (EN) rats in response to bilateral infusion of the selective MC4-R antagonist HS014 (0, 0.02 or $0.05 \mu \mathrm{g} / 0.5 \mu \mathrm{l} / \mathrm{site})$ or the selective MC4-R agonist cyclo(NH-CH $2-\mathrm{CH}_{2}$-CO-His-D-Phe-Arg-Trp-Glu)- $\mathrm{NH}_{2}(0,0.75$ or $1.5 \mu \mathrm{g} / 0.5 \mu \mathrm{l} / \mathrm{site})$, into the lateral hypothalamus ( $\mathrm{LH}$ ), the nucleus accumbens (NAc), or the ventral tegmental area (VTA). The main findings in the study are: 1) LH-infusions of the MC4-R antagonist increased and the agonist reduced feeding and total calories consumed, while ethanol intake remained unaltered. 2) NAc- and VTA-infusions of the selective agonist reduced food, ethanol and total calories intake. 3) NAc- and VTA-infusions of the MC4-R antagonist increased feeding in EN rats, but not in EE animals which showed a mild increase in ethanol intake, while total calories consumed remained unaltered. Present data show that having ethanol available reduces feeding elicited by NAc and VTA-MC4-R blockade. Additionally, while MC4-R signalling in the LH appears to modulate homeostatic aspects of feeding, it may contribute to non-homeostatic aspects of ingestive behaviours in the VTA and the NAc.

\section{Keywords}

feeding; ethanol; MC4 receptors; lateral hypothalamus; nucleus accumbens shell; ventral tegmental area

\footnotetext{
(C) 2012 Elsevier B.V. All rights reserved.

*Address for correspondence: Dra. Inmaculada Cubero, Departamento de Neurociencia y Ciencias de la Salud, Universidad de Almería, 04120 Almería, Spain, Fax: 950-015473, icubero@ual.es.

Publisher's Disclaimer: This is a PDF file of an unedited manuscript that has been accepted for publication. As a service to our customers we are providing this early version of the manuscript. The manuscript will undergo copyediting, typesetting, and review of the resulting proof before it is published in its final citable form. Please note that during the production process errors may be discovered which could affect the content, and all legal disclaimers that apply to the journal pertain.
} 


\section{Introduction}

The Melanocortin (MC) system has been extensively studied for its role in energy balance.

This system possesses an endogenous agonist, a-melanocyte stimulating hormone (a-MSH) and an inverse agonist, Agouti-related peptide (AgRP), which are downstream factors of leptin [1] and show opposing actions on the same MC receptors [2,3]. There is an established role for the MC signaling within the hypothalamus in modulating feeding behaviour, body weight regulation [4-7] and food selection [8] by homeostatic mechanisms [1,9], and more recently it has been suggested that MC signaling in limbic structures might regulate non-homeostatic aspects of feeding $[1,5,10]$.

The MC system, with a special emphasis on MC4 receptor (MC4-R), is clearly involved in animal models of obesity and anorexia-cachexia [11-15]. Moreover, MC receptors (MC-R) are currently a promising target system for the development of drugs aimed to treat obesity and eating disorders in humans [8,16-19]. MC peptides that might be employed to treat feeding disorders also have other biological activities that involve MC4-R signaling. In this regard, recent pharmacological and genetic studies have provided additional evidence that MC play a role in ethanol consumption in ethanol preferring strains. Thus, intracerebroventricular (i.c.v.) infusion of the non-selective MC3-R/MC4-R agonist Melanotan-II (MTII) decreases ethanol consumption in C57BL/6J mice [20] and AA rats [21]. I.c.v. infusion of the non-selective MC3-R/MC4-R inverse agonist Agouti-related protein (AgRP)-(83-132) disrupts MTII-induced reduction of ethanol consumption [20] and increases voluntary ethanol consumption in C57BL/6J mice [22]. Consistent with pharmacological studies, genetic deletion of AgRP blunts ethanol self-administration and binge-like ethanol drinking [23]. Furthermore, i.c.v. infusion of MTII reduces ethanol

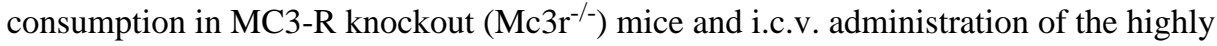
selective MC4-R agonist cyclo(NH- $\mathrm{CH}_{2}-\mathrm{CH}_{2}$-CO-His-D-Phe-Arg-Trp-Glu)- $\mathrm{NH}_{2}$ significantly decreases voluntary ethanol consumption and feeding in C57BL/6J mice [22], supporting a role for the MC4-R.

A growing body of experimental evidence suggests the existence of overlapped neurobiological systems for food and ethanol intake [24]. In this regard, there is pharmacological evidence showing that some feeding peptides might lack their orexigenic activity while selectively stimulate ethanol intake in Sprague-Dawley (SD) rats [25], a strain which shows low voluntary ethanol intake on average and spontaneous drinking patterns commensurate with a model of social drinking. Thus, administration of the orexigenic peptides orexin or galanin, but not ghrelin, into the appropriate locus in the hypothalamus increased ethanol intake while food consumption remained unaltered in ethanol drinking rats [25]. These data raise the possibility that having ethanol available might modify the anorectic/orexigenic activity of centrally administered feeding compounds in low-ethanol drinkers.

Taking into account that low/moderate ethanol drinking is widely extended in our society some important questions remain unaddressed from the perspective of using specific MC-R as drug targets with a focus on the treatment of anorexia/cachexia and other eating disorders in humans. First, whether having ethanol available alters the anorectic/orexigenic activity of MC4-R compounds; second, whether a MC4-R antagonist triggering feeding may also induce ethanol drinking in animals showing low ethanol consumption baseline; third, the anatomical sites and mechanisms that mediate these effects.

The present study evaluates food intake in SD rats while drinking ethanol in response to a selective MC4-R antagonist and agonist infused into the lateral hypothalamus (LH), the nucleus accumbens shell (NAc) or the ventral tegmental area (VTA), which are brain 
regions in which MC signaling might be involved in the homeostatic (LH) and nonhomeostatic (NAc, VTA) $[1,8,10]$ aspects of food intake. We compare here feeding in response to site-directed MC4-R compounds in ethanol-naïve (EN) and ethanol exposed (EE) SD rats, which show low ethanol drinking baseline. Additionally, we test here if centrally-infused MC4-R compounds do significantly alter voluntary ethanol consumption.

\section{Methods}

\subsection{Animals}

Male Sprague-Dawley rats (Charles River Laboratories, Spain) weighing 280-300 g at the beginning of the experiments were housed individually in an environmentally controlled room $\left(22^{\circ} \mathrm{C}\right.$ temperature on a $12: 12 \mathrm{~h}$ light:dark cycle). Standard rodent chow and water were provided ad libitum throughout the experiments and all the pharmacological manipulations were conducted at the onset of the dark phase. Behavioral procedures and pharmacological techniques were in compliance with the animal care guidelines established by the Spanish Royal Decrees 1025/2005 for reducing animal pain and discomfort and the protocols were approved by the University of Almería Bioethical Animal Care and Use Committee.

\subsection{Surgery}

Rats were anesthetized with equitesin $(0.3 \mathrm{ml} / 100 \mathrm{~g})$ and surgically implanted with a bilateral 26-G cannula (Plastic One Inc., Germany) aimed at the LH, the NAc, or the VTA using the following stereotaxic coordinates: $\mathrm{LH}-2.12 \mathrm{~mm}$ posterior to bregma, $2.10 \mathrm{~mm}$ lateral to the midline and $8 \mathrm{~mm}$ ventral to the skull surface; NAc $1.7 \mathrm{~mm}$ anterior to bregma, $0.8 \mathrm{~mm}$ lateral to the midline, and $5.4 \mathrm{~mm}$ ventral to the skull surface; VTA $-5.3 \mathrm{~mm}$ posterior to bregma, $0.6 \mathrm{~mm}$ lateral to the midline, and $8 \mathrm{~mm}$ ventral to the skull surface [26]. Rats were allowed to recover for approximately 10 days before any experimental manipulation. After the conclusion of experimental procedures, histological verification of cannula placement was conducted.

\subsection{Assessment of food and ethanol consumption following bilateral site-directed infusion of selective MC4-R compounds}

The present study included two independent groups: 1) Ethanol-exposed group (EE). Rats in this group were allowed to drink ethanol for four weeks prior to experimental manipulations and also had ethanol available during the pharmacological challenge. 2) Ethanol-naïve group $(E N)$. Rats in this group were never exposed to ethanol and had no ethanol available during the pharmacological challenge.

Once the animals recovered from stereotaxic surgery (10 days) and before rats were given central infusions of drugs, $24 \mathrm{~h}$ baseline measures of body weight, food consumption, and water consumption were collected for one month. During this time, EE animals were given 24-h free access to ethanol. They had access to two bottles, one containing plain water and the other containing a solution of ethanol in plain water $(6 \% \mathrm{w} / \mathrm{v})$, for one month. The positions of the bottles were changed every 2 days to control for position preferences. Throughout the experiments, ethanol (only EE group) (g/kg/24-h), food consumption (g/kg/ $24-\mathrm{h})$ and water consumption $(\mathrm{ml} / \mathrm{kg} / 24-\mathrm{h})$ were assessed. We carefully checked for any spilled food so final food measures were calculated by subtracting weights between measures and accounting for any food spillage.

Procedure for administration of MC4-R compounds-Following one month in which baseline measures were collected, all rats in both conditions (EE and EN) were weighted and distributed into 3 sub-groups based on average ethanol consumption ( $\mathrm{g} / \mathrm{kg} / 24$ - 
h) during the preceding 4 days for the EE group, or based on average food consumption for the EN group. One hour before the beginning of the dark phase of the light:dark cycle, rats were weighed and ethanol, water and food were removed from the cages. Then, rats were given bilateral site-directed infusion of the selective MC4-R antagonist HS014 (Phoenix Pharmaceuticals, Inc., Belmont, CA) dissolved in isotonic saline in a dose of either 0.02 or $0.05 \mu \mathrm{g} / 0.5 \mu \mathrm{l} / \mathrm{site}$ or an equal volume of isotonic saline $(0.5 \mu \mathrm{l} / \mathrm{site})$ into the $\mathrm{LH}$, NAc or the VTA ( $\mathrm{n}=10$ per treatment in each group). The selected doses of the MC4-R antagonist HS014 significantly increase feeding in rats when infused into the CeA [14] during light phase. Site-directed infusions were given manually over a one minute period with a $1.0 \mu \mathrm{l}$ Hamilton syringe connected to a 33-G injector cannula (Plastic One Inc., Germany) that protruded $1 \mathrm{~mm}$ when aimed to the NAc; and $0.2 \mathrm{~mm}$ when aimed to the LH and VTA. The injector remained in place for an additional 60 seconds prior to removal to prevent reflux. Then, rats were immediately returned to their home cage. Ethanol, water and food were returned to the cages for EE animals and food and water for EN animals, within a period of 15 minutes post-drug treatment. Intake measures were recorded 2-h and 4-h post-infusion.

One week later, when consumption measures were stabilized and returned back to baseline levels, rats were re-distributed into 3 new groups based on average ethanol consumption for EE group or food consumption for EN group and then infused with the selective MC4-R agonist cyclo(NH- $\mathrm{CH}_{2}-\mathrm{CH}_{2}$-CO-His-D-Phe-Arg-Trp-Glu)- $\mathrm{NH}_{2}$ (Phoenix Pharmaceuticals, Inc., Belmont, CA) dissolved in isotonic saline, at either 1.5 or $0.75 \mu \mathrm{g} / 0.5 \mu \mathrm{l} / \mathrm{site}$ or an identical volume of isotonic saline $(0.5 \mu \mathrm{l} / \mathrm{site})$ into the LH, NAc or the VTA ( $\mathrm{n}=10$ per treatment in each group). The selected doses of the MC4-R agonist were based on previous studies showing decreased feeding and ethanol consumption in C57BL/6J mice following i.c.v. infusions [22]. Post-drug infusion data collection procedures were the same as described for the HSO14 compound above.

\subsection{Histology}

Rats were anesthetized with equitesin $(0.3 \mathrm{ml} / 100 \mathrm{~g})$ and injected with $0.5 \mu \mathrm{l}$ methyl green (Sigma-Aldrich, Spain) prior to cardiac perfusion to verify injection sites (Figure 1). The brains were removed, post-fixed in paraformaldehyde for $48 \mathrm{~h}$ at $4^{\circ} \mathrm{C}$ and transferred to PBS. Cerebral sections were cut in coronal section $50 \mu \mathrm{m}$ thick with a motorized vibrotome. Behavioral data from animals with injector tips in the right brain site were included in the statistical analysis, while those with tips out from the target regions (1-3 per treatment in each group) were discarded from the analysis.

\subsection{Statistical analyses}

Non cumulative food consumption in response to site-directed infusions of selective MC4-R antagonist/agonist in EE and EN groups were analyzed with a $3 \times 2 \times 2$ (Treatment $\times$ Time $\times$ Group) mixed factor repeated measures analyses of variance (ANOVA) that evaluated short-term effects of site-directed infusions of two doses of the selective MC4-R compound or saline, at 2- and 4-h post-infusion in ethanol-exposed and ethanol naïve rats. Additionally, non-cumulative ethanol consumption and total fluid consumption (ethanol + water) data in EE rats, as well as water consumption data in EN rats, were analyzed with independent $3 \times 2$ (Treatment $\times$ Time) mixed factor repeated measures ANOVA, which evaluated ingestive behaviors in response to saline or two possible doses of the MC4-R compound, 2- and 4-h post-infusion. Finally, total calories (cal/kg/4-h) (calories from chow in EN rats and calories from chow + ethanol solution in EE rats) consumed for 4-h post-treatment were analyzed with independent $3 \times 2$ (Treatment $\times$ Group) ANOVAs. Statistically significant interaction effects were analyzed by the simple-effect analysis strategy and pair-wise comparisons of means were tested by using Bonferroni correction [27]. To simplify the results section, only statistically significant data are presented. Finally, we provide the size effect $\left(\eta^{2}\right)$ for each 
analysis which yielded significant results. In order to reduce the total number of analysis in the text, we will provide the results obtained for the main effects and those relevant interactions for our study aimed to evaluate whether MC4-R signaling in specific brain sites modulate ethanol and food intake, in which Treatment is a factor (Treatment $\times$ Time, Treatment $\times$ Group, Treatment $\times$ Group $\times$ Time).

\section{Results}

\subsection{Effects of the selective MC4-R antagonist HS014 on food consumption}

Lateral Hypothalamus-Figure 2a represents non-cumulative food consumption data in two 2-h intervals following LH infusion of the MC4-R antagonist HS014 to EE and EN rats. The analyses performed revealed statistically significant Time $[F(1,46)=53.7 ; p=0.00$; partial $\left.\eta^{2}=0.54\right]$, Treatment $\left[F(2,46)=6.06 ; p=0.00 ;\right.$ partial $\left.\eta^{2}=0.22\right]$ and Group $[F(1$, 46) $=15.38 ; p=0.00 ;$ partial $\left.\eta^{2}=0.25\right]$ main effects. With regard to the main effect of Time, the data indicated that both groups of rats consumed more food during the first two hours of testing. With regard to the main effect of Treatment, pair-wise comparisons revealed that $0.05 \mu \mathrm{g}$ and $0.02 \mu \mathrm{g}$ doses of the antagonist significantly increased feeding relative to saline. Finally, rats in the EN group consumed more food that those in the EE group.

The ANOVA performed on water consumption by EN rats revealed a statistically significant main effect of Treatment $\left[F(2,24)=6.7 ; p=0.00 ;\right.$ partial $\left.\eta^{2}=0.36\right]$. Additional post hoc analysis showed that $0.02 \mu \mathrm{g}$ and $0.05 \mu \mathrm{g}$ dose of the antagonist significantly increased water consumption relative to saline (data not shown).

Nucleus Accumbens-Figure $2 b$ represents non-cumulative food consumption data in two 2-h intervals following NAc infusion of the MC4-R antagonist HS014 to EE and EN rats. The analyses performed on non-cumulative food consumption data revealed statistically significant Time $\left[\mathrm{F}(1,35)=17.12 ; \mathrm{p}=0.00 ;\right.$ partial $\eta^{2}=0.33$; food consumption at $2-4$ hours interval $>0-2$ hours interval], and Group $\left[F(1,35)=44.3 ; p=0.00 ;\right.$ partial $\eta^{2}=0.56$; food consumption: EN group $>$ EE group] main effects. Treatment $\times$ Group interaction attained statistical significance $\left[\mathrm{F}(2,35)=5.47 ; \mathrm{p}=0.00\right.$; partial $\left.\eta^{2}=0.30\right]$ and additional pair-wise comparisons showed that the EN group showed higher food consumption compared to the EE group in response to both doses of the MC4-R antagonist. Additionally, no group differences emerged in food consumption following saline administration.

The ANOVA performed on water consumption by EN rats following site-directed infusion of the MC4-R antagonist HS014 did not show statistically significant main effects or interactions (data not shown).

Ventral Tegmental Area-Figure 2c represents non-cumulative food consumption data in two 2-h intervals following VTA infusion of the MC4-R antagonist HS014 to EE and EN rats. The analyses performed revealed a statistically significant Time main effect $[F(1,41)=$ 5.44; $p=0.02$; partial $\eta^{2}=0.12$ ], showing that food consumption was higher during the first two hours tested. The Group $\times$ Treatment interaction attained statistical significance $[\mathrm{F}(2$, $41)=6.77 ; p=0.00 ;$ partial $\left.\eta^{2}=0.25\right]$ and additional pair-wise comparisons showed that VTA administration of $0.02 \mu \mathrm{g}$ of HS014 increased food consumption, but only in the EN group.

The ANOVA performed on water consumption by EN rats revealed a statistically significant Treatment main effect $\left[F(2,17)=4.3 ; p=0.03\right.$; partial $\left.\eta^{2}=0.33\right]$. Post hoc analysis revealed that VTA-administration of $0.02 \mu \mathrm{g}$ of HS014 significantly increased water consumption relative to saline and $0.05 \mu \mathrm{g}$ (data not shown). 


\subsection{Effects of the selective MC4-R antagonist HS014 on ethanol consumption in EE animals}

Lateral Hypothalamus-Figure 3a represents non-cumulative ethanol consumption data for two 2-h intervals following LH infusion of the MC4-R antagonist HS014 to EE rats. The $3 \times 2$ (Treatment $\times$ Time) analysis of variance performed on ethanol consumption data did not reveal statistical significance of any main factor or interaction. The ANOVA performed on total fluid consumption data did not reveal statistical significance for Treatment and Time main effects or Time $\times$ Treatment interaction.

Nucleus Accumbens-Figure $3 \mathrm{~b}$ represents non-cumulative ethanol consumption data for two 2-h intervals following NAc infusion of the MC4-R antagonist HS014 to EE rats. The ANOVA performed on ethanol consumption data revealed a statistically significant Time main effect, $\left[F(1,18)=12.84 ; p=0.00 ;\right.$ partial $\left.\eta^{2}=0.42\right]$, showing that ethanol consumption was higher for all subjects at the first 2-h tested, and Treatment main effect [F $(2,18)=3.77 ; p=0.04 ;$ partial $\eta^{2}=0.30$ ]. Additional post hoc analysis revealed that 0.02 $\mu \mathrm{g}$ dose of the antagonist significantly increased ethanol consumption relative to $0.05 \mu \mathrm{g}$, but not relative to saline.

The ANOVA performed on total fluid consumption revealed statistically significant Time main effect $\left[\mathrm{F}(1,18)=8.42 ; \mathrm{p}=0.01 ;\right.$ partial $\left.\eta^{2}=0.31\right]$ indicating that total fluid consumption was higher for all subjects during the first 2-h interval tested (data not shown).

Ventral Tegmental Area-Figure 3c represents non-cumulative ethanol consumption data for two 2-h intervals following VTA infusion of the MC4-R antagonist HS014 to EE rats. The ANOVA performed on ethanol consumption data revealed no statistical significance of Treatment and Time main effects or Treatment $\times$ Time interaction. On the other hand, the ANOVA performed on total fluid consumption did not show statistical significance of Time and Treatment main effects or Time $\times$ Treatment interaction.

\subsection{Effects of the selective MC4-R antagonist HS014 on total calories consumed}

Lateral Hypothalamus-The ANOVA performed on total calories (cal $/ \mathrm{kg} / 4-\mathrm{h}$ ) consumed for 4-h post-treatment revealed statistically significant Treatment $[\mathrm{F}(2,46)=5.6 ; \mathrm{p}=0.006]$ and Group $[\mathrm{F}(1,46)=9.4 ; \mathrm{p}=0.003]$ main effects. Additional pair-wise comparisons showed that compared to saline, both doses of the MC4-R antagonist significantly increased caloric intake (Table 1). Treatment $\times$ Group interaction did not attain statistical significance.

Nucleus Accumbens-The ANOVA performed on total calories consumed for 4-h posttreatment did (cal/kg/4-h) reveal no statistically significant Treatment, Group main effects or Treatment $\times$ Group interaction (Table 1 ).

Ventral Tegmental Area-The ANOVA performed on total calories (cal/kg/4-h) consumed for 4-h post-treatment did reveal no statistically significant Treatment or Treatment $\times$ Group interaction. The group main effect attained statistical significance [F (1, $41)=4.4 ; \mathrm{p}=0.04]($ Table 1$)$

\subsection{Effects of the selective MC4-R agonist cyclo(NH-CH$\left.-\mathrm{CH}_{2}-\mathrm{CO}-H i s-D-P h e-A r g-T r p-G l u\right)-$ $\mathrm{NH}_{2}$ on food consumption}

Lateral Hypothalamus-Figure 4a represent data showing non-cumulative food consumption for two 2-h intervals following LH infusion of the selective MC4-R agonist to $\mathrm{EE}$ and EN rats. The analyses performed on non-cumulative food consumption data revealed only statistical significance of Treatment main factor $\left[F(2,41)=11.2 ; p=0.00 ;\right.$ partial $\eta^{2}=$ 
0.35]. Post hoc analysis revealed that administration of 0.75 and $1.5 \mu \mathrm{g}$ doses significantly decreased food consumption relative to saline.

The ANOVA performed on water consumption by EN rats revealed statistically significant main effect for Treatment $\left[\mathrm{F}(2,24)=3.8 ; \mathrm{p}=0.03\right.$; partial $\left.\eta^{2}=0.24\right]$. Additional post hoc analysis revealed that $0.75 \mu \mathrm{g}$ and $1.5 \mu \mathrm{g}$ doses of the selective MC4-R agonist reduced water consumption relative to saline (data not shown).

Nucleus Accumbens-Figure $4 \mathrm{~b}$ represent data showing non-cumulative food consumption for two 2-h intervals following NAc infusion of the selective MC4-R agonist to $\mathrm{EE}$ and $\mathrm{EN}$ rats. The analyses performed on non-cumulative food consumption data revealed statistically significant Treatment $\left[\mathrm{F}(2,35)=22.16 ; \mathrm{p}=0.00\right.$; partial $\left.\eta^{2}=0.56\right]$, Time $[\mathrm{F}(1$, $35)=15.2 ; p=0.00 ;$ partial $\left.\eta^{2}=0.31\right]$, and Group main effects $[F(1,35)=20.07 ; p=0.00$; partial $\left.\eta^{2}=0.36\right]$. Also, Time $\times$ Group attained statistical significance $[F(1,35)=10.20 ; p$ $=0.00 ;$ partial $\eta^{2}=0.33$. With regard to Treatment main effect, post hoc analysis revealed that administration of $0.75 \mu \mathrm{g}$ and $1.5 \mu \mathrm{g}$ doses of the agonist significantly decreased food consumption relative to saline. On the other hand, the analysis of Time $\times$ Group interaction showed that EE rats, but not EN rats, reduced feeding at the second 2-h interval.

The ANOVA performed on water consumption by EN rats revealed statistically significant Time $\left[\mathrm{F}(1,17)=13.8 ; \mathrm{p}=0.00 ;\right.$ partial $\eta^{2}=0.45$ (2 hours $>4$ hours $\left.)\right]$ and Treatment $[\mathrm{F}(2$, 17) $=5.07 ; p=0.02 ;$ partial $\left.\eta^{2}=0.37\right]$ main effects. Post hoc analysis revealed that administration of $0.75 \mu \mathrm{g}$ and $1.5 \mu \mathrm{g}$ doses significantly decreased water consumption relative to saline (data not shown).

Ventral Tegmental Area-Figure $4 \mathrm{c}$ represents data showing non-cumulative food consumption for two 2-h intervals following VTA infusion of the selective MC4-R agonist to EE and EN rats. The analyses performed on non-cumulative food consumption data revealed statistically significant Time $\left[\mathrm{F}(1,41)=15.5 ; \mathrm{p}=0.00\right.$; partial $\eta^{2}=0.27$ (2 hours $>4$ hours $)]$, and Treatment $\left[\mathrm{F}(2,41)=19.6 ; \mathrm{p}=0.00\right.$; partial $\left.\eta^{2}=0.49\right]$ main effects. Post hoc analysis revealed that administration of $0.75 \mu \mathrm{g}$ and $1.5 \mu \mathrm{g}$ doses significantly decreased feeding relative to saline.

The ANOVA performed on water consumption by EN rats revealed statistically significant main effects for Time $\left[\mathrm{F}(1,17)=8.16 ; \mathrm{p}=0.01\right.$; partial $\eta^{2}=0.32$ ( 2 hours $>4$ hours) $]$, and Treatment $\left[F(2,17)=13.5 ; p=0.00 ;\right.$ partial $\left.\eta^{2}=0.61\right]$. Post hoc analysis revealed that administration of $0.75 \mu \mathrm{g}$ and $1.5 \mu \mathrm{g}$ doses significantly decreased water consumption relative to saline (data not shown).

\subsection{Effects of the selective MC4-R agonist cyclo( $\left.\mathrm{NH}-\mathrm{CH}_{2}-\mathrm{CH}_{2}-\mathrm{CO}-\mathrm{His}-\mathrm{D}-\mathrm{Phe}-\mathrm{Arg}-\mathrm{Trp}-\mathrm{Glu}\right)-$ $\mathrm{NH}_{2}$ on ethanol consumption in EE animals}

Lateral Hypothalamus-Figure 5a represents data showing ethanol consumption for two 2-h intervals following LH infusion of the MC4-R agonist to EE rats. The mixed $3 \times 2$ analysis of variance performed on ethanol consumption data revealed only statistically significance for the main effect Time $\left[F(1,17)=6.13\right.$; $p=0.02$; partial $\left.\eta^{2} 0.26\right]$ showing that ethanol consumption was higher during the first $0-2 \mathrm{~h}$ interval for all subjects.

The ANOVA performed on total fluid consumption revealed a statistically significant Time main effect $\left[F(1,17)=14.11 ; p=0.001 ;\right.$ partial $\left.\eta^{2}=0.45\right]$ indicating that total fluid consumption was higher for all subjects during the $0-2 \mathrm{~h}$ interval, and Treatment $[\mathrm{F}(2,17)$ $=7.88 ; \mathrm{p}=0.0038 ;$ partial $\left.\eta^{2}=0.48\right]$. Additional post hoc analysis revealed that both 0.75 $\mu \mathrm{g}$ and $1.5 \mu \mathrm{g}$ doses of the agonist significantly reduced total fluid consumption relative to saline (data not shown). 
Nucleus Accumbens-Figure 5b represents data showing ethanol consumption for two 2-h intervals following NAc infusion of the MC4-R agonist to EE rats. The ANOVA performed on data revealed statistically significant main effects for Time $[F(1,18)=12 ; p=$ 0.003; partial $\eta^{2}=0.40$ ], showing that ethanol consumption was higher at the first 2-h tested for all subjects; and for Treatment $\left[F(2,18)=3.62 ; p=0.04\right.$; partial $\left.\eta^{2}=0.30\right]$. Additional post hoc analysis revealed that both $0.75 \mu \mathrm{g}$ and $1.5 \mu \mathrm{g}$ doses of the agonist significantly reduced ethanol consumption relative to saline.

On the other hand, the analysis of variance performed on total fluid consumption revealed statistically significant main effects for Time $\left[\mathrm{F}(1,18)=14.51 ; \mathrm{p}=0.001 ;\right.$ partial $\eta^{2}=$ $0.45]$, showing that total fluid consumption was higher at the first 2 -h interval, and for Treatment $\left[\mathrm{F}(2,18)=3.90 ; \mathrm{p}=0.03\right.$; partial $\left.\eta^{2}=0.30\right]$. Additional post hoc analysis revealed that $1.5 \mu \mathrm{g}$ dose of the agonist significantly reduced total fluid consumption relative to saline (data not shown).

Ventral Tegmental Area-Figure 5c represents data showing ethanol consumption for two 2-h intervals following VTA infusion of the MC4-R agonist to EE rats. The ANOVA performed on data revealed only a statistically significant main effect of Treatment $[\mathrm{F}(2$, 24) $=6.26 ; p=0.00 ;$ partial $\left.\eta^{2}=0.34\right]$. Additional post hoc analysis revealed that both 0.75 $\mu \mathrm{g}$ and $1.5 \mu \mathrm{g}$ doses of the agonist significantly reduced ethanol consumption relative to saline.

The ANOVA performed on total fluid consumption revealed a statistically significant main effect Time $\left[F(1,24)=7.3 ; p=0.01 ;\right.$ partial $\left.\eta^{2}=0.23\right]$, showing that total fluid consumption was higher at the first two hours tested; and Treatment $[\mathrm{F}(2,18)=3.90 ; \mathrm{p}=$ 0.03; partial $\eta^{2}=0.30$ ]. Additional post hoc analysis revealed that $0.75 \mu \mathrm{g}$ of the agonist significantly reduced total fluid consumption relative to saline (data not shown).

\subsection{4. Effects of the selective MC4-R agonist $c y c l o\left(N H-\mathrm{CH}_{2}-\mathrm{CH}_{2}-\mathrm{CO}-\mathrm{His}-\mathrm{D}-\mathrm{Phe}\right.$-Arg-Trp- Glu)- $\mathrm{NH}_{2}$ on total calories consumed}

Lateral Hypothalamus-The ANOVA performed on total calories consumed for 4-h post-treatment $(\mathrm{cal} / \mathrm{kg} / 4-\mathrm{h})$ revealed a statistically significant Treatment main effect [F (2, $41)=19.59 ; \mathrm{p}=0.00]$. Additional pair-wise comparisons showed that both doses of the MC4-R agonist significantly reduced total calories consumed (Table 1). Group main effect and Treatment $\times$ Group interaction did not attain statistical significance.

Nucleus Accumbens-The ANOVA performed on total calories consumed for 4-h posttreatment $(\mathrm{cal} / \mathrm{kg} / 4-\mathrm{h})$ revealed a statistically significant Treatment main effect $[\mathrm{F}(2,35)=$ $18.79 ; \mathrm{p}=0.00]$. Additional pair-wise comparisons showed that both doses of the MC4-R agonist significantly reduced total calories consumed (Table 1). Group main effect and Treatment $\times$ Group interaction did not attain statistical significance.

Ventral Tegmental Area-The ANOVA performed on total calories consumed for 4-h post-treatment $(\mathrm{cal} / \mathrm{kg} / 4-\mathrm{h})$ revealed a statistically significant Treatment main effect $[\mathrm{F}(2$, $41)=20.37 ; p=0.00]$. Additional pair-wise comparisons showed that both doses of the MC4-R agonist significantly reduced total calories consumed (Table 1). Group main effect and Treatment $\times$ Group interaction did not attain statistical significance

\section{Discussion}

MC4-Rs are currently a promising target system for the development of drugs aimed to treat eating disorders in humans $[8,16-19]$. Because there is previous evidence that some feeding peptides might lack their orexigenic activity while selectively stimulate ethanol intake in 
low ethanol drinkers [25], it is important to characterize feeding behavior in response to MC pharmacological challenges in animals having ethanol available. The present study was aimed to evaluate food intake in ethanol-naïve and ethanol drinking SD rats, a strain showing low rates of voluntary ethanol consumption, when infused with a selective MC4-R antagonist or agonist into limbic regions, VTA and NAc, or into the LH, a key relay-region between the hypothalamus and the limbic circuits $[1,5,8,10]$. We also tested if centrallyinfused MC4-R compounds alter voluntary ethanol consumption in SD rats which show low ethanol consumption as average.

The main findings in the study are: 1) LH infusion of the selective MC4-R antagonist increased and the agonist reduced feeding correlated with a significant reduction in total caloric intake both in EE and EN group. Voluntary ethanol drinking remained unaltered in response to both pharmacological (agonist/antagonist) manipulations; 2) NAc and VTA administration of the selective MC4-R antagonist increased feeding in EN rats but this effect was not evident in EE animals drinking ethanol. Ethanol consumption was mildly (but not significantly) stimulated in EE rats and interestingly, net caloric intake over the 4-h testing period remained unaltered, both in EE and EN rats; 3) Administration of the selective agonist into the NAc or VTA reduced feeding in both EN and EE animals and significantly reduced ethanol consumption in EE animals; total caloric intake was significantly reduced as well. Because stimulation of MC4-R has been associated with increased grooming [28, 29] and previous studies have reported no significant changes in locomotor activity following administration of MC4-R agonist [29, 30], it is unlikely that agonist-induced reductions in ingestive behaviors were the result of a generalized behavioural inhibition.

Fluid consumption (water in the EN group and total fluid in the EE group) after MC pharmacological challenges seemed to be coupled to feeding patterns. Thus, animals showing increased food consumption after MC4-R antagonists also showed an increase in water consumption; inversely, agonism on MC4-R elicited a parallel reduction in food and water intake, suggesting the secondary nature of the effects of MC manipulations on water consumption. Nonetheless, because there is evidence that MC signaling may modulate fluid consumption unrelated to food intake [31,32], we cannot rule out that present observations regarding fluids reflex the primary and specific control of MC4-R signaling over fluid balance.

Because the MC4-R antagonist HS014 is a cyclic peptide that has more than 300-fold selectivity for rat MC4-R over rat MC3-R [33] and cyclo(NH-CH $2-\mathrm{CH}_{2}$-CO-His-D-PheArg-Trp-Glu)- $\mathrm{NH}_{2}$, is a highly selective agonist for MC4-R, with 90-fold selectivity over MC3-R and a 3400-fold selectivity over MC5-R [34], the converging set of present data indicates that endogenous MC signaling in the LH, VTA and NAc regulates feeding via the MC4-R.

\subsection{Lateral hypothalamus}

The first relevant observation in the study is that administration of 0.02 or $0.05 \mu \mathrm{g}$ of the selective antagonist HS014 into the LH increased food intake. Alternatively, administration of 0.75 or $1.5 \mu \mathrm{g}$ of the selective MC4-R agonist strongly reduced feeding in both EE and EN animals, indicating that MC4-R signaling in the LH contributes to food intake modulation and that ethanol availability does not seem to modify the orexigenic ability of LH-infused MC4-R compounds. Because both doses of the antagonist increased and the agonist reduced total calories consumed over the testing period we conclude that intake disturbances observed after LH-infusion of selective MC4-R compounds were caloricdriven, which supports the idea that MC4-R signaling into the LH might be involved in the homeostatic aspects of food intake. 
Our present results are in agreement with the role played by the LH in energy balance as one site bridging brain systems modulating the homeostatic and non-homeostatic aspects of feeding [31]. The LH contains two main sub-populations of cells contributing to energy balance [35] that produce orexigenic peptides: orexin (OX) and melanin concentrating hormone (MCH). LH OX- cells express a high density of MC4-R [36-38] and there is pharmacological evidence that MC signaling within these cells contributes to food intake. Thus, LH AAV-agouti injected rats developed obesity when exposed to a high-fat diet [39]; feeding induced by i.c.v. administration of the endogenous inverse agonist AgRP was associated to increased c-fos activation in OX-cells in the LH [40]; LH infusions of the aMSH analog, NDP-MSH, triggered a delayed decrease in food intake 8-h post treatment [41] and pro-opiomelanocortin-deficient mice, a mouse model lacking all endogenously produced melanocortin peptides, showed an elevation in orexin levels contributing to hyperphagia [37]. The present observations add relevant information to previous studies evaluating the role of MC4-R signaling in hypothalamic areas by showing that LH administration of a selective MC4-R agonist reduces and the antagonist increases feeding and total caloric intake, unrelated to ethanol availability. Additionally, they reinforce the idea that LH OX- and/or MCH-producing cells are downstream factors of MC signaling via MC4-R.

\subsection{Nucleus accumbens and ventral tegmental area}

The second relevant observation in the study is that the selective MC4-R antagonist increased and the agonist reduced food consumption, when infused into the VTA and the NAc in EN rats having no ethanol available.

Regarding the effects of the selective MC4-R agonist, VTA- and NAc- infusion of $0.75 \mu \mathrm{g}$ or $1.5 \mu \mathrm{g}$ triggered a strong anorectic response both in animals having ethanol available and ethanol-naive animals, correlated with a significant reduction in total calories consumed over the 4-h testing period, both in EE and EN rats. Additionally, both doses of the agonist significantly decreased ethanol consumption. These data are in agreement with the well known anorectic effect that follows acute stimulation of hypothalamic MC4-R [1,10]; whether common or independent neurobehavioural mechanisms contributed to intake disturbances following hypothalamic (LH) vs limbic (VTA, NAc) MC4-R stimulation remains unclear and needs further testing.

Regarding the effect of the selective MC4-R antagonist in animals having no ethanol available (EN), feeding was significantly increased after NAc administration of 0.02 or 0.5 $\mu \mathrm{g}$ of HS014 while only the lowest dose employed $(0.02 \mu \mathrm{g})$ increased feeding when infused into the VTA. The statistical analysis did not support relevant increases in feeding during the second interval tested after VTA-infusion of the high dose of HS104; however, the presence of a positive trend might be indicative of the existence of a delayed orexigenic effect at the highest dose employed, which is consistent with previous observations that MC4-R blockade may trigger long-term feeding [1]. Also, regional differences in MC4-R densities may explain variability in regional sensitivity to MC compounds [42, 43]. Nonetheless, it is worthy note that total calories consumed over the 4-h testing period by EN rats remained unaltered in all the antagonist-treatment conditions, an observation to which we will be back in short.

The third relevant observation in the present study was that animals having ethanol available (EE group) did not show that increase in feeding shown by EN rats following NAc or VTA administration of a selective MC4-R antagonist. By contrast, VTA and NAc-infusion of 0.02 $\mu \mathrm{g}$ of the selective MC4-R antagonist mildly although not significantly, stimulated ethanol consumption. This observation is consistent with previous evidence showing that administration of the orexigenic neuropeptides orexin or galanin into the appropriate locus 
in the hypothalamus stimulates ethanol intake while the expected orexigenic effect on food intake is blunted [25]. However, given that ethanol intake by EE rats was not accompanied by a net increase in caloric intake it is tempting to speculate that NAc- and VTA-infusion of the selective MC4-R antagonist altered the preferred caloric source (from chow to ethanol) while total calories ingested remained perfectly adjusted. The observations that VTA- and NAc- infusion of a selective MC4-R antagonist have an impact on feeding in EN rats and ethanol intake in EE rats, while total calories intake remain unaltered in both conditions, are consistent with a role for MC4-R signaling in limbic circuitry modulating non-homeostatic aspects of intake. Given that present results are based on direct intake measures, we cannot provide a conclusion regarding those specific non-homeostatic mechanism/s involved, yet some tentative ideas are next offered.

In the NAc and the VTA, opioid signaling exerts relevant influences on feeding [44, 45] and ethanol intake [46, 47], both by dependent and independent hedonic-driven processes [4852]. Thus, Mu-opioid receptors in the NAc-shell regulate taste hedonics and feeding of palatable substances $[49,50,53]$; low doses of Naltrexone reduces consumption and taste reactivity of palatable foods [54,55], ethanol palatability and ethanol intake as well, in outbred rats $[48,50,56]$. Interestingly, there is experimental evidence linking opioids to MC signaling. Thus, pre-treatment with the MC-R agonist MTII blocks ethanol-induced alterations of Met-enkephalin- $\mathrm{Arg}^{6} \mathrm{Phe}^{7}$ (MEAP) immunoreactivity in the ventral tegmental area [21]. MCs antagonize opiate dependence and tolerance [57] and administration of a non-selective MC-R agonist blocks the antinociceptive effects of opioids, whereas MC4-R antagonists enhance opioid antinociception $[58,59]$. Taking together the aforementioned data, it is tempting to speculate that NAc-infusion of the selective MC4-R antagonist HS014 enhanced and the agonist reduced, endogenous opioid signaling, contributing in opposite ways to subsequent increases or decreases in regular chow intake by EN rats and ethanol consumption by EE rats. Whether changes in ingestive behaviour observed after limbic MC4-R manipulations were driven by primary hedonic disturbances remains unknown and call for specific taste reactivity studies aimed to address the hypothesis that MC signaling in the NAc regulates hedonic aspects of ethanol/food consumption.

\subsection{Conclusions}

Administration of a selective MC4-R antagonist into the LH, the NAc and the VTA increased and the agonist reduced feeding in ethanol naive animals. In ethanol drinking animals, when the MC antagonist was infused into the NAc shell or the VTA, but not into the lateral hypothalamic region, the orexigenic effect was not shown, while ethanol was mildly stimulated. The MC system, with a special emphasis on MC4-R, is clearly involved in animal models of obesity and anorexia/cachexia [11-15] and MC-Rs are currently a target system for the development of drugs aimed to treat obesity and eating disorders in humans $[8,16-19]$. Present data indicates that drinking ethanol, even at low rates, may cause significant long-term alterations in ethanol consumption and/or the expected orexigenic response induced by MC4-R antagonists when administered in the appropriate brain locus.

Interestingly, only lateral hypothalamic MC4-R blockade significantly increased total caloric intake, which raised the interesting hypothesis that MC4-R signaling within the LH contributes to homeostatic aspects of feeding while in the NAc and the VTA, it regulates non-homeostatic aspects of ingestive behaviours. Additional studies are now being conducted in our laboratory aimed to further characterize neurobehavioural mechanisms underlying MC control of ethanol and food intake within limbic regions. 


\section{Acknowledgments}

This work was supported by MEC grants (Spain), SEJ2006-03629, PSI2009-07677 "Programa Salvador Madariaga 2006", J.A., grant CTS1350, FEDER UALM05-23-006, NIH grants AA013573, AA015148, and the Department of Defense grants W81XWH-06-1-0158 and W81XWH-09-1-0293.

\section{References}

1. Pandit R, de Jong JW, Vanderschuren LJ, Adan RA. Neurobiology of overeating and obesity: The role of melanocortins and beyond. Eur J Pharmacol. 2011; 660:28-42. [PubMed: 21295024]

2. Cone RD. Anatomy and regulation of the central melanocortin system. Nat Neurosci. 2005; 8:5718. [PubMed: 15856065]

3. De Jonghe BC, Hayes MR, Bence KK. Melanocortin control of energy balance: evidence from rodent models. Cell Mol Life Sci. 2011; 68:2569-88. [PubMed: 21553232]

4. Adan RA, Tiesjema B, Hillebrand JJ, la Fleur SE, Kas MJ, de Krom M. The MC4 receptor and control of appetite. Br J Pharmacol. 2006; 149:815-27. [PubMed: 17043670]

5. Harrold JA, Williams G. Melanocortin-4 receptors, beta-MSH and leptin: key elements in the satiety pathway. Peptides. 2006; 27:365-71. [PubMed: 16290320]

6. Irani BG, Haskell-Luevano C. Feeding effects of melanocortin ligands--a historical perspective. Peptides. 2005; 26:1788-99. [PubMed: 16046247]

7. Vergoni AV, Bertolini A. Role of melanocortins in the central control of feeding. Eur J Pharmacol. 2000; 405:25-32. [PubMed: 11033311]

8. Hillebrand JJ, Kas MJ, Adan RA. To eat or not to eat; regulation by the melanocortin system. Physiol Behav. 2006; 89:97-102. [PubMed: 16574172]

9. Ellacott KL, Cone RD. The role of the central melanocortin system in the regulation of food intake and energy homeostasis: lessons from mouse models. Philos Trans R Soc Lond B Biol Sci. 2006; 361:1265-74. [PubMed: 16815803]

10. Davis JF, Choi DL, Shurdak JD, Krause EG, Fitzgerald MF, Lipton JW, Sakai RR, Benoit SC. Central melanocortins modulate mesocorticolimbic activity and food seeking behaviour in rat. Physiol Behav. 2011; 102:491-5. [PubMed: 21172367]

11. Boghossian S, Park M, York DA. Melanocortin activity in the amygdala controls appetite for dietary fat. Am J Physiol Regul Integr Comp Physiol. 2010; 298:385-93.

12. DeBoer MD. Melanocortin interventions in cachexia: how soon from bench to bedside? Current Opin Clin Nutr Metab Care. 2007; 10:457-62.

13. Giraudo SQ, Billington CJ, Levine AS. Feeding effects of hypothalamic injection of melanocortin 4 receptor ligands. Brain Res. 1998; 809:302-6. [PubMed: 9853124]

14. Kask A, Schiöth HB. Tonic inhibition of food intake during inactive phase is reversed by the injection of the melanocortin receptor antagonist into the paraventricular nucleus of the hypothalamus and central amygdala of the rat. Brain Res. 2000; 887:460-4. [PubMed: 11134642]

15. Vergoni AV, Bertolini A, Mutulis F, Wikberg JE, Schiöth HB. Differential influence of a selective melanocortin MC4 receptor antagonist (HS014) on melanocortin-induced behavioral effects in rats. Eur J Pharmacol. 1998; 362:95-101. [PubMed: 9874158]

16. Adan RA, van Dijk G. Melanocortin receptors as drug targets for disorders of energy balance. CNS Neurol Disord Drug Targets. 2006; 5:251-61. [PubMed: 16787227]

17. DeBoer MD. Update on melanocortin interventions for cachexia: progress toward clinical application. Nutrition. 2010; 26:146-51. [PubMed: 20004082]

18. Laviano A, Inui A, Marks DL, Meguid MM, Pichard C, Rossi Fanelli F, Seelaender M. Neural control of the anorexia-cachexia syndrome. Am J Physiol Endocrinol Metab. 2008; 295:E1000-8. [PubMed: 18713954]

19. Moriya J, Takimoto Y, Yoshiuchi K, Shimosawa T, Akabayashi A. Plasma agouti-related protein levels in women with anorexia nervosa. Psychoneuroendocrinology. 2006; 31:1057-61. [PubMed: 16904835] 
20. Navarro M, Cubero I, Knapp DJ, Thiele TE. MTII-induced reduction of voluntary ethanol drinking is blocked by pretreatment with AgRP-(83-132). Neuropeptides. 2003; 37:338-44. [PubMed: 14698676]

21. Ploj K, Roman E, Kask A, Hyytia P, Schioth HB, Wikberg J, Nylander I. Effects of melanocortin receptor ligands on ethanol intake and opioid levels in alcohol-preferring AA rats. Brain Res Bull. 2002; 59:97-104. [PubMed: 12379439]

22. Navarro M, Cubero I, Chen AS, Chen HY, Knapp DJ, Breese GR, Marsh DJ, Thiele TE. Effects of melanocortin receptor activation and blockade on ethanol intake: a possible role for the melanocortin-4 receptor. Alcohol Clin Exp Res. 2005; 29:949-57. [PubMed: 15976520]

23. Navarro M, Cubero I, Ko L, Thiele TE. Deletion of agouti-related protein blunts ethanol selfadministration and binge-like drinking in mice. Genes Brain Behav. 2009; 8:450-8. [PubMed: 19566712]

24. Thiele TE, Navarro M, Sparta D, Fee J, Knapp DJ, Cubero I. Alcoholism and obesity: overlapping neuropeptide pathways? Neuropeptides. 2003; 37:321-37. [PubMed: 14698675]

25. Schneider ER, Rada P, Darby RD, Leibowitz SF, Hoebel BG. Orexigenic peptides and alcohol intake: differential effects of orexin, galanin, and ghrelin. Alcohol Clin Exp Res. 2007; 31:185865. [PubMed: 17850217]

26. Paxinos, G.; Watson, C. The rat brain in stereotaxic coordinates. 4. New York: Academic Press; 1998.

27. Keppel, G. Design and Analysis: A Researcher's Handbook. 3. Prentice- Hall; 1991.

28. Bertolini A, Tacchi R, Vergoni AV. Brain effects of melanocortins. Pharmacol Res. 2009; 1:1347. [PubMed: 18996199]

29. Klenerová V, Krejcí I, Sída P, Hlinák Z, Hynie S. Effects of melanotan II, a melanocortin agonist, on grooming and exploration in rats after repeated restraint/immobilization. Neurosci Lett. 2008; 432:202-5. [PubMed: 18191328]

30. Pfluger PT, Castañeda TR, Heppner KM, Strassburg S, Kruthaupt T, Chaudhary N, Halem H, Culler MD, Datta R, Burget L, Tschöp MH, Nogueiras R, Perez-Tilve D. Ghrelin, peptide YY and their hypothalamic targets differentially regulate spontaneous physical activity. Physiol Behav. 2011; 105:52-61. [PubMed: 21554896]

31. van Dijk G, Evers SS, Guidotti S, Thornton SN, Scheurink AJ, Nyakas C. The lateral hypothalamus: a site for integration of nutrient and fluid balance. Behav Brain Res. 2011; 221:481-7. [PubMed: 21300111]

32. Clegg DJ, Air EL, Benoit SC, Sakai RS, Seeley RJ, Woods SC. Intraventricular melaninconcentrating hormone stimulates water intake independent of food intake. Am J Physiol Regul Integr Comp Physiol. 2003; 284:R494-9. [PubMed: 12557891]

33. Lindblom J, Schiöth HB, Watanobe H, Suda T, Wikberg JE, Bergström L. Downregulation of melanocortin receptors in brain areas involved in food intake and reward mechanisms in obese (OLETF) rats. Brain Res. 2000; 852:180-5. [PubMed: 10661510]

34. Bednarek MA, MacNeil T, Kalyani RN, Tang R, Van der Ploeg LH, Weinberg DH. Selective, high affinity peptide antagonists of alpha-melanotropin action at human melanocortin receptor 4: their synthesis and biological evaluation in vitro. J Med Chem. 2001; 44:3665-72. [PubMed: 11606131]

35. Swanson LW, Sanchez-Watts G, Watts AG. Comparison of melanin-concentrating hormone and hypocretin/orexin mRNA expression patterns in a new parceling scheme of the lateral hypothalamic zone. Neurosci Lett. 2005; 387:80-84. [PubMed: 16084021]

36. Elias CF, Saper CB, Maratos-Flier E, Tritos NA, Lee C, Kelly J, Tatro JB, Hoffman GE, Ollmann MM, Barsh GS, Sakurai T, Yanagisawa M, Elmquist JK. Chemically defined projections linking the mediobasal hypothalamus and the lateral hypothalamic area. J Comp Neurol. 1998; 402:442459. [PubMed: 9862320]

37. Lopez M, Lage R, Tung YC, Challis BG, Varela L, Virtue S, O'Rahilly S, Vidal-Puig A, Diéguez $\mathrm{C}$, Coll AP. Orexin expression is regulated by alpha-melanocyte-stimulating hormone. J Neuroendocrinol. 2007; 19:703-7. [PubMed: 17680885]

38. Hanada R, Nakazato M, Matsukura S, Murakami N, Yoshimatsu H, Sakata T. Differential regulation of melanin-concentrating hormone and orexin genes in the agouti-related protein / 
melanocortin-4 receptor system. Biochem Biophys Res Commun. 2000; 268:88-91. [PubMed: 10652218]

39. Kas MJ, Tiesjema B, van Dijk G, Garner KM, Barsh GS, ter Brake O, Verhaagen J, Adan RA. Induction of brain-region-specific forms of obesity by agouti. J Neurosci. 2004; 24:10176-81. [PubMed: 15537888]

40. Zheng H, Corkern M, Crousillac S, Patterson L, Phifer C, Berthoud H. Neurochemical phenotype of hypothalamic neurons showing Fos expression 23h after intracranial AgRP. Am J Physio Regul Integr Comp Physiol. 2002; 282:1773-81.

41. Kim MS, Rossi M, Abusnana S, Sunter D, Morgan DG, Small CJ, Edwards CM, Heath MM, Stanley SA, Seal LJ, Bhatti JR, Smith DM, Ghatei MA, Bloom SR. Hypothalamic localization of the feeding effect of agouti-related peptide and a-melanocyte-stimulating hormone. Diabetes. 200; 49:177-82. [PubMed: 10868932]

42. Kishi T, Aschkenasi CJ, Lee CE, Mountjoy KG, Saper CB, Elmquist JK. Expresion of melanocortin 4 receptor mRNA in the central nervous system of the rat. J Comp Neurol. 2003; 457:213-35. [PubMed: 12541307]

43. Mountjoy KG, Mortrud MT, Low MJ, Simerly RB, Cone RD. Localizatio of the melanocortin-4 receptor (MC4-R) in neuroendocrine and autonomic control circuits in the brain. Mol Endocrinol. 1994; 8:1298-308. [PubMed: 7854347]

44. Bodnar RJ, Lamonte N, Israel Y, Kandov Y, Ackerman TF, Khaimova E. Reciprocal opioid-opioid interactions between the ventral tegmental area and nucleus accumbens regions in mediating $\mathrm{mu}$ agonist-induced feeding in rats. Peptides. 2005; 26:621-9. [PubMed: 15752577]

45. Mucha RF, Iversen SD. Increased food intake after opioid microinjections into nucleus accumbens and ventral tegmental area of rat. Brain Res. 1986; 397:214-24. [PubMed: 3026557]

46. Oliva JM, Manzanares J. Gene transcription alterations associated with decrease of ethanol intake induced by naltrexone in the brain of Wistar rats. Neuropsychopharmacology. 2007; 32:1358-69. [PubMed: 17063152]

47. Zhang M, Kelley AE. Intake of saccharin, salt, and ethanol solutions is increased by infusion of a mu opioid agonist into the nucleus accumbens. Psychopharmacology (Berl). 2002; 159:415-23. [PubMed: 11823894]

48. Coonfield DL, Hill KG, Kaczmarek HJ, Ferraro FM, Kiefer SW. Low doses of naltrexone reduce palatability and consumption of ethanol in outbred rats. Alcohol. 2002; 26:43-7. [PubMed: 11958946]

49. Peciña S. Opioid reward 'liking' and 'wanting' in the nucleus accumbens. Physiol Behav. 2008:94675-80.

50. Ward HG, Nicklous DM, Aloyo VJ, Simansky KJ. Mu-opioid receptor cellular function in the nucleus accumbens is essential for hedonically driven eating. Eur J Neurosci. 2006; 23:1605-13. [PubMed: 16553624]

51. Diaz-Cenzano E, Chotro MG. The effect of taste familiarity on intake and taste reactivity in infant rats. Dev Psychobiol. 2010; 52:109-20. [PubMed: 20014225]

52. Kiefer SW. Alcohol, palatability, and taste reactivity. Neurosci Biobehav Rev. 1995; 19:133-41. [PubMed: 7770193]

53. Kelley AE, Bakshi VP, Haber SN, Steininger TL, Will MJ, Zhang M. Opioid modulation of taste hedonics within the ventral striatum. Physiol Behav. 2002; 76:365-77. [PubMed: 12117573]

54. Woolley JD, Lee BS, Fields HL. Nucleus accumbens opioids regulate flavor-based preferences in food consumption. Neuroscience. 2006; 143:309-17. [PubMed: 17049180]

55. Woolley JD, Lee BS, Taha SA, Fields HL. Nucleus accumbens opioid signaling conditions shortterm flavor preferences. Neuroscience. 2007; 146:19-30. [PubMed: 17320293]

56. Franck J, Lindholm S, Raaschou P. Modulation of volitional ethanol intake in the rat by central delta-opioid receptors. Alcohol Clin Exp Res. 1998; 22:1185-9. [PubMed: 9756031]

57. Alvaro JD, Tatro JB, Quillan JM, Fogliano M, Eisenhard M, Lerner MR, Nestler EJ, Duman RS. Morphine down-regulates melanocortin-4 receptor expression in brain regions that mediate opiate addiction. Mol Pharmacol. 1996; 50:583-91. [PubMed: 8794897] 
58. Ercil NE, Galici R, Kesterson RA. HS014, a selective melanocortin-4 (MC4) receptor antagonist, modulates the behavioral effects of morphine in mice. Psychopharmacology. 2005; 180:279-85. [PubMed: 15719225]

59. Kalange AS, Kokare DM, Singru PS, Upadhya MA, Chopde CT, Subhedar NK. Central administration of selective melanocortin 4 receptor antagonist HS014 prevents morphine tolerance and withdrawal hyperalgesia. Brain Res. 2007; 1181:10-20. [PubMed: 17915196] 


\section{HIGHLIGHTS}

1. We tested if drinking ethanol alters feeding in response to central MC4R compounds

2. Drinking ethanol reduced feeding induced by NAc and VTA-infused MC4R antagonist

3. Drinking ethanol did not alter feeding induced by LH-infused MC4R antagonist

4. Infusion of the MC4R agonist into the NAc, VTA, but not LH, reduced ethanol intake 
a)

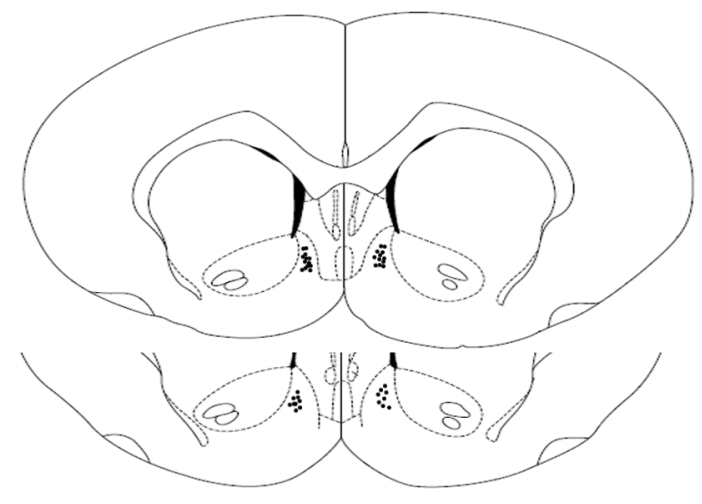

b)

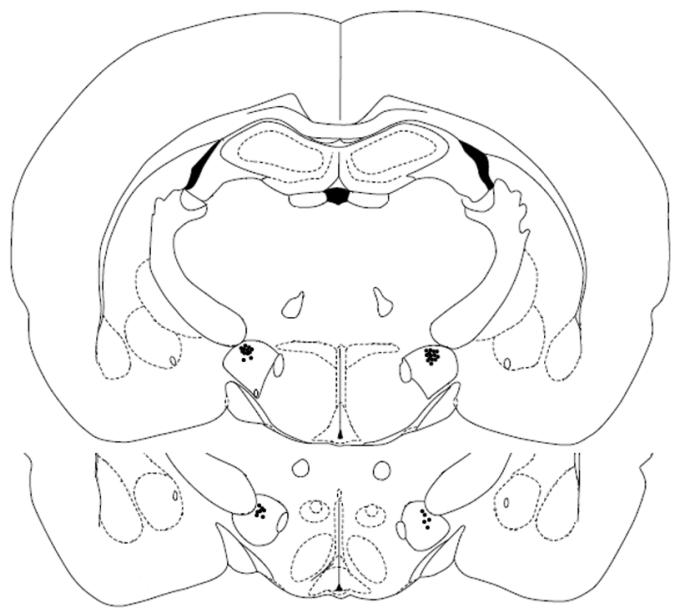

c)

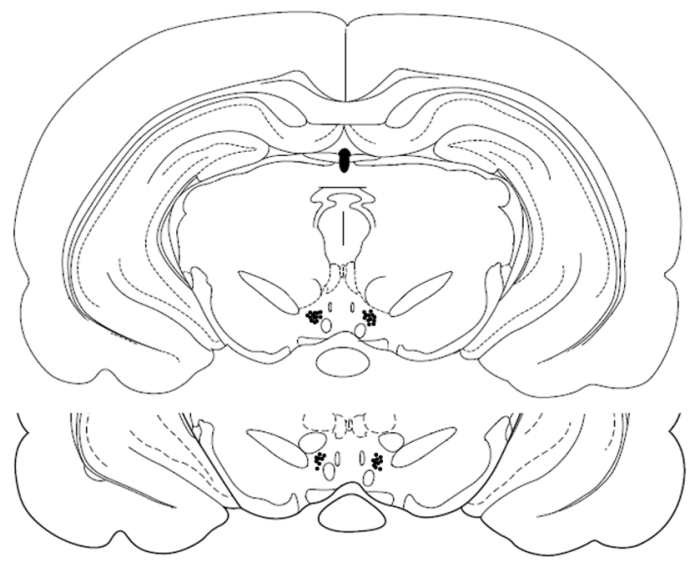

Figure 1.

Histological reconstruction showing injection sites in the NAc (a), LH (b) and VTA (c). Sections are labeled according to the distance from Bregma along the rostral-caudal axis. Adapted from Paxinos \& Watson stereotaxic atlas for rat brain. 

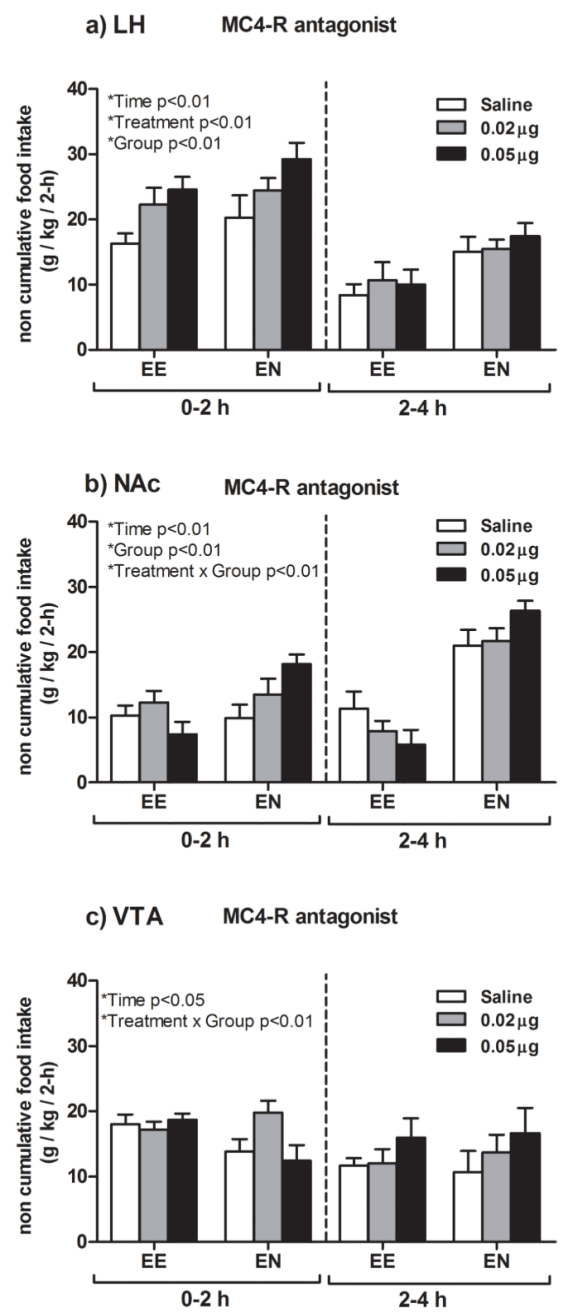

Figure 2.

Graphs represent non-cumulative food consumption in ethanol drinking (EE) and ethanol naïve (EN) rats in two 2-h intervals post-infusion of the selective MC4-R antagonist HS014 $(0.02$ or $0.05 \mu \mathrm{g})$, or isotonic saline into the LH (a), NAc (b) or VTA (c). Pair-wise comparisons showed that relative to saline, administration of HSO14 into the LH increased feeding in ethanol naïve (EN) and ethanol drinking (EE) rats at both doses and two 2-h intervals. NAc-infused HSO14 triggered an orexigenic effect at both doses and during the two 2-h intervals tested only in ethanol naïve rats. VTA infusion of the low dose of HS014 significantly increased feeding during the first 2-h interval relative to saline and only in EN rats; it did not significantly affect food intake in any group over the second interval tested. All values are means \pm S.E.M. 


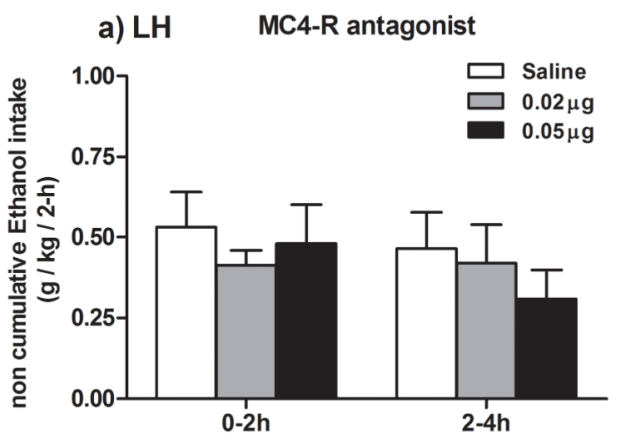

b) NAC MC4-R antagonist

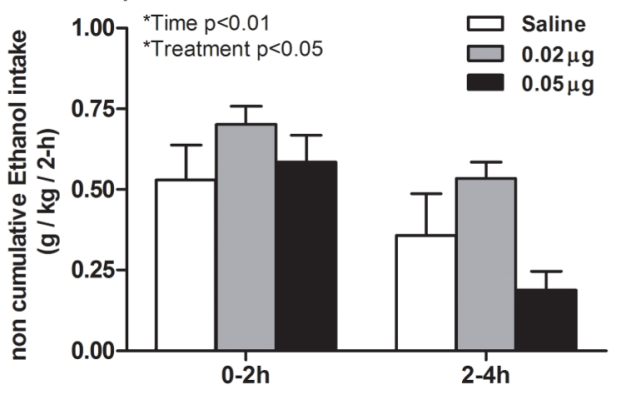

c) VTA MC4-R antagonist

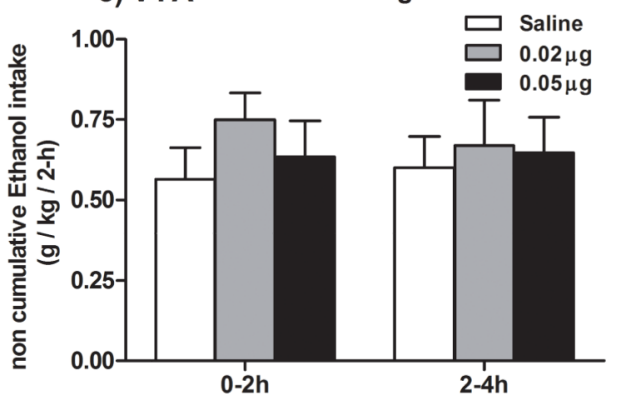

Figure 3.

Graphs represent non-cumulative ethanol consumption $(6 \%(\mathrm{w} / \mathrm{v}), 2$ - and 4-h post-infusion of the selective MC4-R antagonist HS014 (0.02 or $0.05 \mu \mathrm{g}$ ) or isotonic saline into the LH (a), NAc (b) or VTA (c). Pair-wise comparisons showed that MC4-R blockade into the LH and VTA did not significantly alter voluntary ethanol consumption at any time-point tested, although a positive trend to increase ethanol emerged in NAc and VTA-infused animals during the first 2-h tested. HS014 did increase voluntary ethanol consumption at the low dose relative to the high dose but not saline, when infused into the NAc. All values are means \pm S.E.M. 

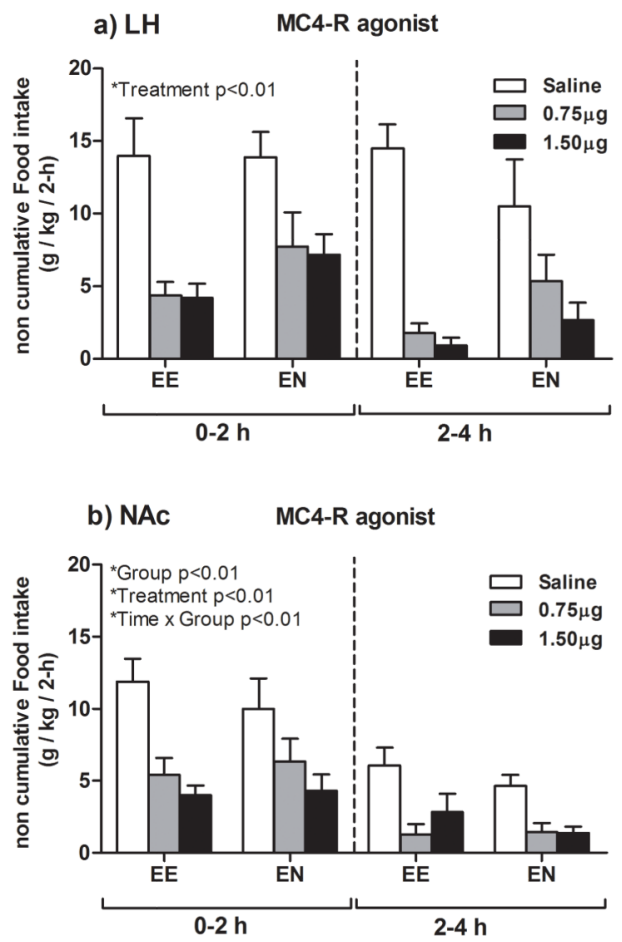

c) VTA MC4-R agonist

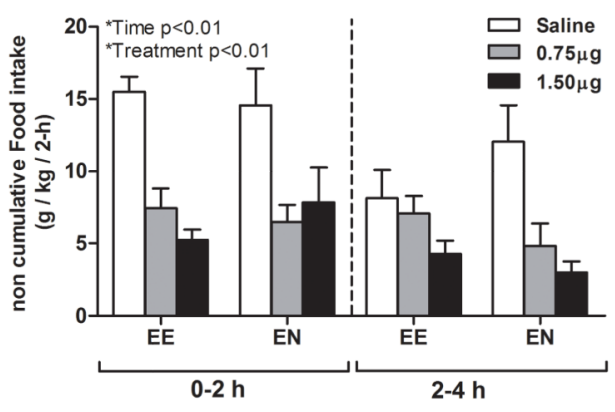

Figure 4.

Graphs represent non-cumulative food consumption in ethanol drinking (EE) and ethanol naïve (EN) rats 2- and 4-h post-infusion of the selective $\mathrm{MC} 4-\mathrm{R}$ agonist cyclo $\left(\mathrm{NH}-\mathrm{CH}_{2}\right.$ $\mathrm{CH}_{2}$-CO-His-D-Phe-Arg-Trp-Glu)- $\left.\mathrm{NH}_{2}\right)(0.75$ or $1.5 \mu \mathrm{g})$ or isotonic saline into the $\mathrm{LH}$ (a), NAc (b) or VTA (c). Pair-wise comparisons showed that relative to saline, both doses of the agonist decreased food consumption over the two 2-h intervals measured when infused into the LH, NAc and VTA, both in the EE and the EN group. All values are means \pm S.E.M. 


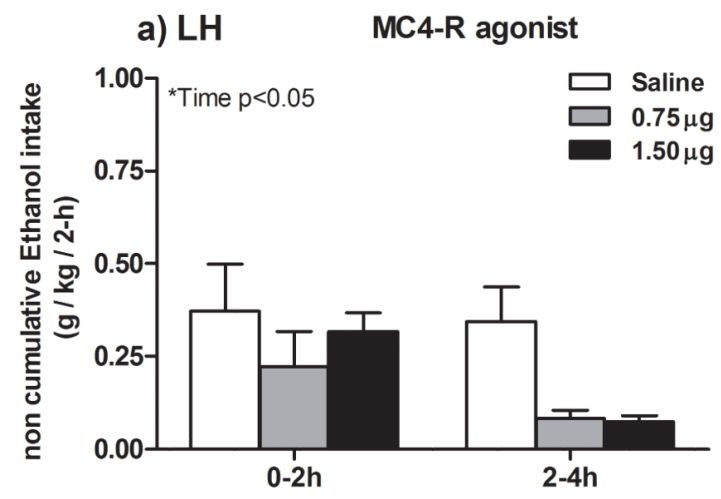

b) NAC MC4-R agonist

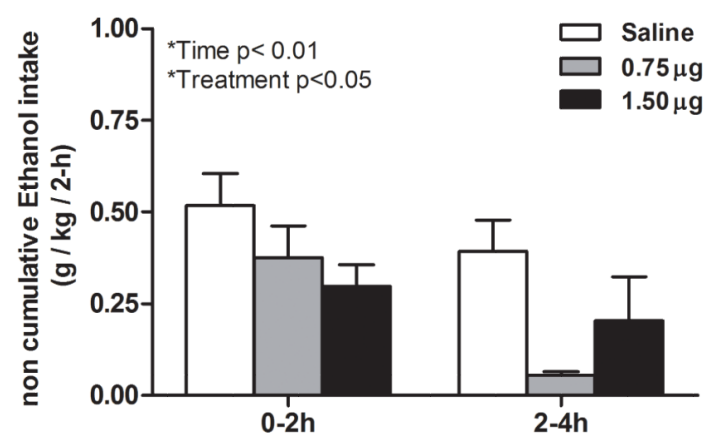

c) VTA MC4-R agonist

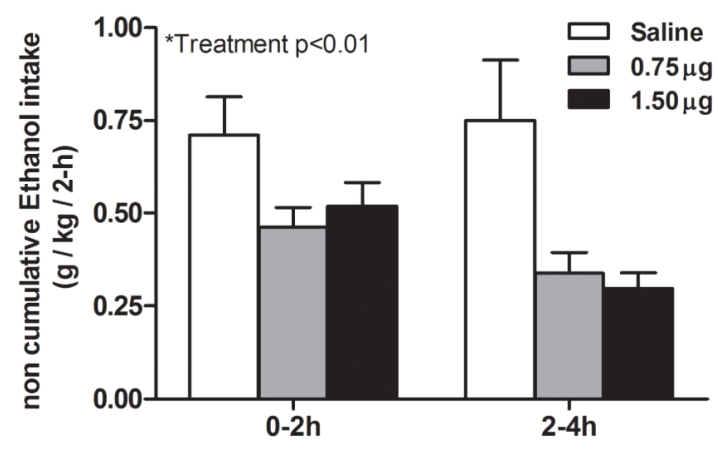

Figure 5.

Graphs represent non-cumulative ethanol consumption (6\% (w/v), 2- and 4-h post-infusion of the selective MC4-R agonist cyclo(NH-CH $2-\mathrm{CH}_{2}$-CO-His-D-Phe-Arg-Trp-Glu)- $\mathrm{NH}_{2}$ ) $(0.75$ or $1.5 \mu \mathrm{g})$ or isotonic saline into the LH (a), NAc (b) or VTA (c). LH-infusion of the agonist did not alter ethanol consumption significantly at any dose employed. By contrast, pair-wise comparisons showed that NAc- and VTA- administration of either 0.75 or $1.5 \mu \mathrm{g}$ reduced ethanol intake relative to saline, during the two 2-h intervals tested. All values are means \pm S.E.M. 


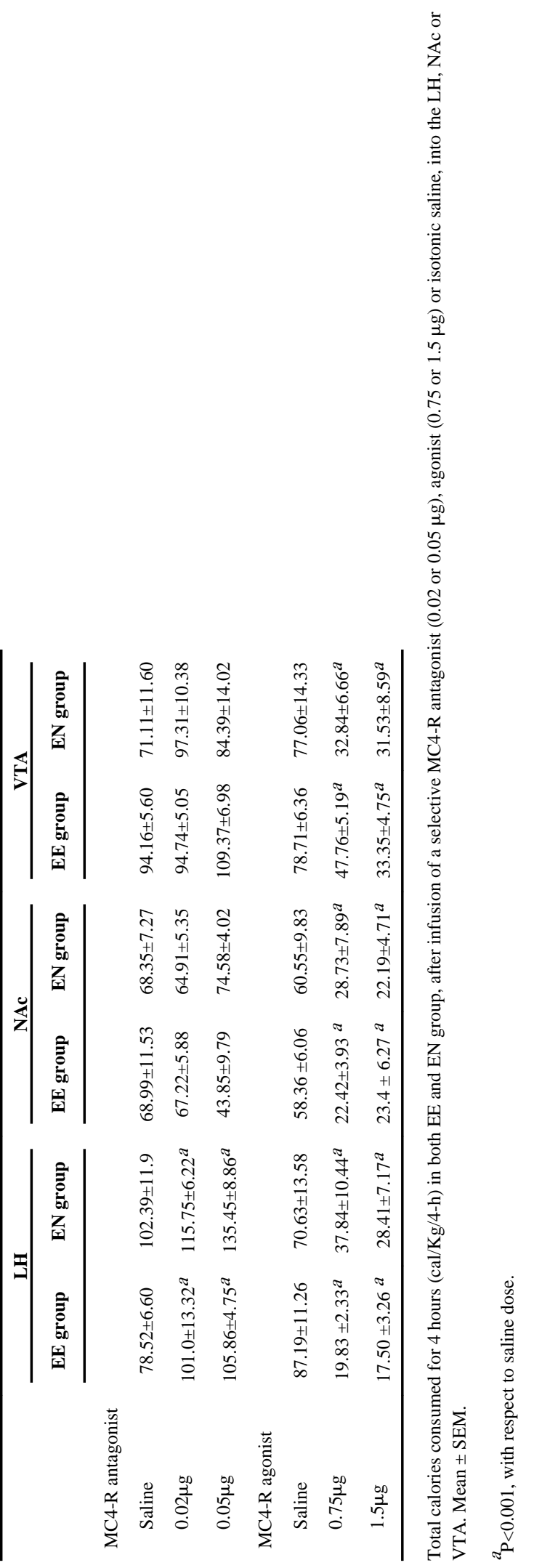

